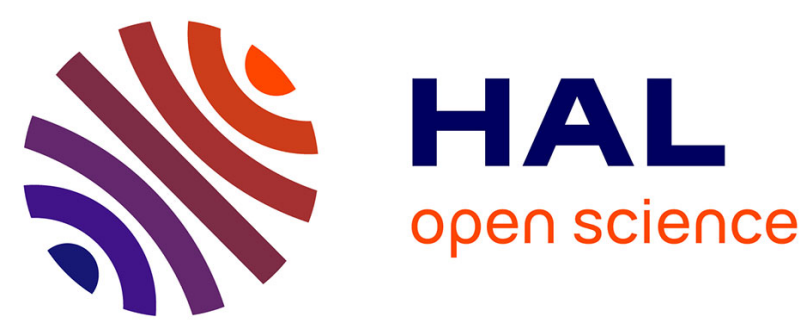

\title{
A water-table dependent reservoir model to investigate the effect of drought and vascular plant invasion on peatland hydrology.
}

Stéphane Binet, Sébastien Gogo, Fatima Laggoun-Défarge

\section{- To cite this version:}

Stéphane Binet, Sébastien Gogo, Fatima Laggoun-Défarge. A water-table dependent reservoir model to investigate the effect of drought and vascular plant invasion on peatland hydrology.. Journal of Hydrology, 2013, 499, pp.132-139. 10.1016/j.jhydrol.2013.06.035 . insu-00812402

\section{HAL Id: insu-00812402 \\ https://hal-insu.archives-ouvertes.fr/insu-00812402}

Submitted on 12 Apr 2013

HAL is a multi-disciplinary open access archive for the deposit and dissemination of scientific research documents, whether they are published or not. The documents may come from teaching and research institutions in France or abroad, or from public or private research centers.
L'archive ouverte pluridisciplinaire HAL, est destinée au dépôt et à la diffusion de documents scientifiques de niveau recherche, publiés ou non, émanant des établissements d'enseignement et de recherche français ou étrangers, des laboratoires publics ou privés. 
A water-table dependent reservoir model to investigate the effect of drought and vascular plant invasion on peatland hydrology.

Stéphane Binet ${ }^{1,2,3 *}$, Sébastien Gogo ${ }^{1,2,3}$, Fatima Laggoun-Défarge ${ }^{1,2,3}$

${ }^{1}$ Université d'Orléans, CNRS/INSU, BRGM, ISTO, UMR 7327, 45071, Orléans, France

2, ISTO, UMR 7327, 45071 Orléans, France

3, ISTO, UMR 7327, BP 36009, 45060 Orléans, France

*Corresponding author

E-mail address: stephane.binet@univ-orleans.fr

Institut des Sciences de la Terre d'Orléans : ISTO UMR 7327 Université d'Orléans, CNRS/INSU, BRGM

Tel : (+) 33238492596

Fax : (+) 33238636488 
ABSTRACT:

This paper investigates the water table dynamics in a peatland showing a wide range of water table fluctuations. A reservoir model of water table fluctuations in a double-porosity peat is proposed, by calculating the stored water in effective porosity of the peat from precipitation and evapotranspiration datasets. Calculations conceptualize vascular plant consumption through a crop coefficient. Changes in water storage, located in the effective porosity of the peat, are described through a maximum infiltration rate and a maximum storage capacity. Water discharges take place in runoff and percolation reservoirs. The runoff coefficient is considered to be water table dependent. This model was tested on a peatland that has experienced strong water table fluctuations caused by summer drought and/or by vascular plant water consumption. A water table dependent runoff model appeared to be adequate to describe the water table fluctuations in peatland. From this model, vascular plants were found to increase the crop coefficient and to limit percolation through the peat. The high water table depth in winter was found to change with the year and is related to an equilibrium between slow infiltration in peat versus percolation plus evapotranspiration. In this disturbed peatland, even if overland flows occurred after a drought, the re-saturation of effective porosity was slow with about $30 \%$ of air trapped in the porosity 6 months after the drought period. The effects of drought on peat saturation were observed over more than a single hydrological cycle. This can affect the biogeochemical processes controlling the $\mathrm{C}$ cycle in peatland.

Key words: Peatland ; Hydrological model ; water balance; storage capacity; plant consumption 


\section{Introduction:}

Peatland ecosystems are the major natural continental carbon (C) store as well as an important $\mathrm{CH}_{4}$ source (Gorham, 1991, Morris et al., 2011). Their response to global change is uncertain as positive or negative feedback can be triggered (Lashof et al., 1997). This uncertainty creates the need to better assess and predict their $\mathrm{C}$ source or sink functioning to be able ultimately to take the peatland contribution into account in the global climate model (Limpens et al., 2008). In the carbon cycle, hydrological functioning controls the physical, chemical and biological processes (Weiss et al., 2006) and hence is one of the most important factors regulating carbon fluxes.

The usual hydrological conceptual model in peatland, according to Ingram's definition (1983), distinguishes an acrotelm and a catotelm layer. The acrotelm is affected by a fluctuating water table (WT). It is the compartment that supports the growing vegetation and where most of the biological activities take place. The catotelm is a waterlogged compartment which is permanently anoxic and where microbial communities are composed only of strict anaerobic organisms (Holden and Burt 2003). Linked to this microbial activity, Moore and Knowles (1989) showed in laboratory experimental studies of peat cores that the molar ratio of $\mathrm{CO}_{2}$ and $\mathrm{CH}_{4}$ emission may rise from as low as 10 with the WT $10 \mathrm{~cm}$ above the peat, to $>10000$ when the WT is $70 \mathrm{~cm}$ below the peat surface. This relationship between WT and biogeochemistry is also observed in other multi-porosity aquifers, where successive WT fluctuations change the water bicarbonate content in response to $\mathrm{CO}_{2}$ dissolution and modify the water exchanges between the different reservoirs of the aquifers (Charmoille et al., 2009). Thus, because of the control the WT exerts on gas availability within the peat column, WT depth and variations are key factors in understanding the C cycle.

Under environmental changes (such as global warming, precipitation changes or vascular plant invasion), the WT dynamics can change and create feedback effects on the C cycle. Frequent WT drawdowns creating a deeper and thicker acrotelm than is observed in intact peatlands may lead to further degradation and to a reinforcement of the runoff generation by erosion phenomena, change 
the water quality (Daniels et al., 2008) and modify evapotranspiration (Restrepo et al., 1998). This is also evidenced in harvested sites where drainage and peat extraction lower the WT, expose relatively decomposed peat and increase the runoff (Van Seters and Price, 2001), whereas creating artificial drain blocking increases the WT, modifies the runoff and the water quality (Worrall et al., 2007).

To explore WT impact on hydrological processes (runoff and infiltration) and on the carbon cycle, some studies have monitored peatlands located in areas with a higher average air temperature than in sub-boreal peatlands (Rosenberry and Winter, 1997; Sarkkola et al.2009; Gogo et al., 2011a). The mechanisms described in these kinds of peatlands can help to understand how ecosystems situated in high latitudes may react to global change. From a hydrological point of view, the peatlands located in these areas may experience strong summer drought, high WT fluctuations and even higher precipitation (IPCC, 2008).

The second approach is to model these mechanisms to propose prospective scenarios. To do so, hydrological peatland models are based on the regular concept of soil hydrology (Restrepo et al., 1998). For large scale areas and for geochemical modeling, hydrologists usually prefer to apply a reservoir model with a limited number of calibrated parameters (Perrin et al. 2001; Violette et al., 2010). Most hydrological peatland models focus on runoff production (e.g. Quinton et al, 1999; Tetzlaff et al., 2007). Few of them try to model the WT dynamics to evidence possible feedbacks in the hydrological processes.

In this paper, a reservoir model of WT fluctuations in a multi-porosity peat is proposed based on a literature review. The aim was to identify the four parameters that explain more than $80 \%$ of the WT fluctuations, from the precipitation and evapotranspiration datasets. The calculations include: vascular plant consumption through a "crop" coefficient, water supply of peat through a maximum infiltration rate and a maximum water storage capacity and the flows with runoff and percolation coefficients. To improve the description between the WT and other parameters, the runoff 
coefficient is considered to be WT dependent. This model was tested on a peatland that has experienced strong WT fluctuations caused by summer drought and/or by vascular plants.

\section{Materials and methods}

\subsection{Study site}

The site studied is La Guette peatland (Fig. 1) located in Neuvy-sur-Barangeon in the South-East part the French Région Centre, $200 \mathrm{~km}$ south of Paris (altitude: $160 \mathrm{~m}, \mathrm{~N}: 47^{\circ} 19^{\prime}, \mathrm{E}: 2^{\circ} 16$ ). The site is composed of patches of acidic Sphagnum fen with peaty heathland dominated by Calluna vulgaris and Erica tetralix. The site is colonised by Molina caerulea and Betula spp (Betula pendula and Betula pubescens). The dominant Sphagnum species are Sphagnum cuspidatum and Sphagnum rubellum. The maximum peat thickness is $2 \mathrm{~m}$.

\subsection{Field and laboratory measurements}

In March 2009, 268 measurements of WT elevations were made with a level (for elevation) and a Global Positioning System (for $\mathrm{x}$ and $\mathrm{y}$ location) to produce a WT map and to delineate the catchment area of the peatland. The horizontal accuracy was $2 \mathrm{~m}$, the elevation accuracy was $1.8 \mathrm{~cm}$. The results are presented in Figure 1, using a flow accumulation method (Gruber and Peckham, 2009) in a Geographic Information System.

Precipitation was recorded by the French weather institute (Meteo-France) $0.8 \mathrm{~km}$ from the peatland and potential evapotranspiration (ETO) was calculated using a Penman formula from data recorded in the town of Bourges (25 km south-east of the peatland). For the thirty-year period 1971-2000 in Bourges, annual average precipitation was about $732 \mathrm{~mm}$ and annual average ET0 about $831 \mathrm{~mm}$. Between 2008 and 2011, precipitation and ETO were about $767 \mathrm{~mm}$ and $957 \mathrm{~mm}$, respectively. Daily records were not available for the catchment for the overall period of the WT monitoring. The precipitation and ETO datasets were validated by comparing the dataset from the weather institute with datasets from a Campbell scientific weather station ${ }^{\circledast}$ installed on the peatland catchment in 
2010. For the years $2010-2011$, the comparison shows a 1.0 slope and a regression coefficient of about $R^{2}=0.98$ for the precipitation dataset (Table 1 ).

Runoff was measured manually at the Q0 discharge point using a dilution method (described in Binet et al., 2007). An automatic device was installed during the fall of 2011. As the discharge area can be connected with the river during the high water level period, the data do not represent only the outflow of the peat. Manual measurements were performed on each field trip if the river was not connected to the drainage zone.

Within the peatland the WT levels were monitored in four sites: in the western part, site WO is dominated by open vegetation and site WC is dominated by Molinia caerulea and especially Betula spp vegetation, which tend to "close" the system. Two sites were located in the eastern part of the peatland: site DO has an open vegetation and site DC has a closed vegetation (by Molinia caerulea and Betula spp) (Gogo et al., 2011b).

Shallow wells were installed to provide data on the fluctuations of the WT for the four sites (Fig. 1). These wells were constructed by hand-augering a hole and installing a PVC screen and a pipe $5.1 \mathrm{~cm}$ in diameter. The depth was about 1.2 meter. As peat depth was less than $1 \mathrm{~m}$ in the four monitoring sites, the four wells were instrumented with a WT monitoring system (OTT ${ }^{\oplus}$ Orpheus mini and Orphimede). WTs were queried each hour by a data logger and the logs were averaged to provide daily heads. Manual check measurements were made on each field trip to validate the automatic measurements. Water-level accuracy was about $0.001 \mathrm{~m}$.

Following Fetter (1994), the change in water storage in the peat (Sp) caused by WT fluctuations is: $\Delta \mathrm{Sp}=\mathrm{dh}(\phi \mathrm{e}+\mathrm{bSs})($ equation 1$)$ where $\Delta \mathrm{Sp}$ is the change in water stored in the peat for a dh change in the WT, and $\phi \mathrm{e}$ is the effective porosity (assuming an unconfined aquifer). Ss is the specific storage due to peat compressibility and $b$ is the thickness of peat. 
The total, effective and retention porosities $\phi_{T}, \phi_{e}, \phi_{r}$ were determined in the laboratory using $40 \mathrm{~cm}$ diameter cores extracted from the four WT measurement plots. The cores were drained $24 \mathrm{~h}$ and cut into $49.09 \mathrm{~cm}^{3}$ samples (V) every $5 \mathrm{~cm}$ along the peat column using a metallic cylinder. The samples were weighed (W1) and dried for $24 \mathrm{~h}$ at $90^{\circ} \mathrm{C}$, then weighed again (W2). Three replicates were prepared for each sample.

- Total porosity is: $\phi_{\mathrm{T}}=1-\left[\left(\mathrm{W}_{2} / \rho_{\mathrm{t}}\right) / \mathrm{V}\right]$ where $\rho_{\mathrm{t}}$ is the peat density (here 2.2 according to Kennedy and Price, 2005).

- Retention porosity is: $\phi_{\mathrm{r}}=\left[\left(\mathrm{W}_{1}-\mathrm{W}_{2}\right) / \rho_{\mathrm{w}}\right] / \mathrm{V}$ where $\rho_{\mathrm{w}}$ is the water density (here 1$)$.

- Effective porosity is: $\phi_{\mathrm{e}}=\phi_{\mathrm{T}}-\phi_{\mathrm{r}}$.

The Ss term is defined as the amount of water that is expelled from aquifer storage due to compressibility of the soil matrix per unit change in head (Kennedy and Price, 2005), and is calculated as:

$\mathrm{S}_{\mathrm{s}}=(\mathrm{db} / \mathrm{dh}) / \mathrm{b}$ (equation 2$)$

where $\mathrm{db}$ is the change in peat thickness, measured as a change in surface elevation (Van Seters and Price, 2001). Surface elevation changes (db) were monitored at the four well locations with different peat depths by measuring the distance between the Sphagnum capitulum elevation and the top of the wells. The slopes inferred from the WT depth versus peat elevation are estimates of storage changes associated with the mechanism of dilatation storage. The slope divided by the intercept is an estimate of the depth-averaged specific storage (Schlotzhauer and Price, 1999).

Retention and effective porosity were integrated from the bottom of the peat column to the surface to provide the retention and effective stored water amount related to the WT depth (Sr and Se). The maximum storage capacity in effective porosity (Semax) is the amount of stored water when WT depth is null: (Table 2). Changes in the retention and unsaturated reservoir $(\Delta \mathrm{Sr}$ ) were not monitored.

\section{Model description: daily WT fluctuations in the peatland}


A daily conceptual model of WT fluctuations was developed, based on the water balance concept.

Peat is considered as a dual porosity medium (Ours et al., 1996). In dual-porosity aquifers, the WT fluctuations take place in the effective porosity, but the other porosities are key parameters to understand water exchanges between the reservoirs (Charmoille et al., 2009, Charlier et al., 2010). Thus a two-reservoir model, derived from Weiss et al. (2006) and Chaubey and Ward (2006) was designed to describe the WT fluctuations. All the terms discussed below are conceptualized in Figure 2. The units are expressed in liter per square meter or millimeter.

\subsection{Water balance}

A general formulation for the water balance is:

$\mathrm{PP}=\mathrm{ET}+\mathrm{Ron}+\mathrm{Roff}+\mathrm{P}+\Delta \mathrm{Sp}$ (equation 3$)$

where PP is the precipitation, ET is the evapotranspiration, Ron and Roff are horizontal run-on and run-off, respectively, $\mathrm{P}$ is the percolation through the peat and $\Delta \mathrm{Sp}$ is the change in the peat column water storage.

\subsection{Definition of the reservoirs as a function of water storage within the peat column}

The water stored in the peatland (Sp) is divided into 3 reservoirs: (1) the runoff reservoir is located in the highly connected macropores and channels $(\mathrm{Sm})$. The Sm reservoir is an unlimited reservoir and contributes to the overland flows; (2) the percolation reservoir is composed of a smaller and /or deeper part of the effective porosity (Se); the amount of water in this reservoir is limited by a maximum storage capacity (Semax); and (3) the retention reservoir ( $\mathrm{Sr}$ ) with no-flow water. Thus the observed changes in the water storage $(\mathrm{Sp})$ are the sum of storage changes in the macropores and in the effective reservoirs.

\subsection{Evapotranspiration}

For irrigation purposes concerning a given tree species (Wanga et al., 2007), or here for peat invaded by vascular plants, the consumed water use or evapotranspiration (ET) is estimated from ET = Kc ET0 
where $\mathrm{Kc}$ is the crop coefficient used to adjust the known reference crop evapotranspiration (ETO) (Campbell and Williamson, 1997; Spieksma et al. 1997; Binet et al. 2006; Wanga et al., 2007).

Depending on the availability of water in the peatland, the model considers that ET first consumes the water from precipitation and runoff in the Sm reservoir. The amount of evapotranspired water in the Sm reservoir is called ETm. If ET is higher than the water available in the Sm reservoir, then evapotranspiration can use water from the percolation reservoir of the peat (Se). Evapotranspired water in the Se reservoir is called ETe (see $n^{\circ} 2$ in figure 2). When precipitation is higher than evapotranspiration, an effective precipitation (EP) is produced.

\subsection{Infiltration, runoff, and discharge}

Infiltration and runoff are antagonistic processes as when the former increases, the latter decreases in the same magnitude (under constant rainfall intensity). The effective precipitation supplies the runoff reservoir $(\mathrm{Sm})$. Then infiltration takes place at the interface between the runoff $(\mathrm{Sm})$ and the percolation (Se) reservoir (Fig.2). A maximum infiltration rate (Imax) was used to describe the amount of water flowing from the Sm to the Se reservoir (Carlesso et al., 2011). The amount of water infiltrated in the percolation reservoir $(\mathrm{I})$ is the lowest value of the following 3 parameters: the maximum infiltration rate (Imax), the free volume available in the percolation reservoir (Se - Semax), and the amount of water available in the Sm reservoir.

\subsection{Development of a WT dependent runoff model}

In peat two kinds of flow take place. If overland flows occur, water flows through macro-pores (drains and channels) close to the peat surface. Following Holden et al. (2008), the model combines a partially submerged flow in the Sm reservoir for overland flows ( $n^{\circ} 5$ in Figure 2 ) with a fully submerged flow in the Se reservoir for flows which are representative of the depths of flows that percolate across the peatland $\left(n^{\circ} 4\right.$ in figure 2$)$.

According to reservoir model theory (Maillet 1905; Fiorillo, 2011), the percolation rate through the Se reservoir can be considered as following a linear relationship with Se: 
$P=\alpha p . S e($ equation 4)

where $\alpha p$ is the percolation coefficient (unit = 1/day).

Similarly, the Runoff flow rate is described as follows:

$\mathrm{R}=\alpha \mathrm{r} . \mathrm{Sm}$ (equation 5)

Considering a Darcy reservoir, $\alpha$ r can be expressed as follows:

$\alpha r=(K / L) \cdot(\mathrm{S} 1 / \mathrm{S} 2)$ (equation 6) (Fiorillo, 2011)

where S1 is the outflowing section, S2 the watershed area, $\mathrm{K}$ the hydraulic conductivity and $\mathrm{L}$ the characteristic length of the reservoir.

In the literature, runoff is found to decrease with WT depth in accordance with the decreases in macropores with depth (Holden et al., 2008, Daniels et al. 2008). In a regular reservoir model S1 is a constant. To model this relationship between WT and $\alpha$, we propose to define the outflowing surface S1 in equation 5 as WT dependent. Thus $\alpha r$ will change and create a feedback on the runoff generation.

For overland flow, the conceptual model (Figure 2) proposes that the runoff reservoir has a triangular outflow section. For a given water amount in the effective reservoir (Se), the outflowing surface will be:

$\mathrm{S} 1=($ Se.w) $/ 2$ (equation 7$)$

where $w$ is the width of the triangle at the WT surface.

If $\alpha r_{\max }$ is the runoff coefficient when Se = Semax (the peatland is saturated), by combining (5) and (6), and writing S1 as a function of Semax, ar becomes:

$\alpha r=\alpha r_{\max } \cdot(\operatorname{Se} / \text { Semax })^{2}$ (equation 8)

Thus a WT depth dependent runoff rate is proposed (equation 9):

$\mathrm{R}=\alpha \mathrm{r}_{\max } \cdot(\mathrm{Se} / \mathrm{Semax})^{2} \cdot \mathrm{Sm}$ (equation 9) 
where $\alpha r_{\max }$. (Se/Semax) $)^{2}$ is the WT dependent runoff coefficient. A Runoff coefficient close to 1 means that all the water from precipitation is evacuated in less than one time step of the model (here 1 day). If $\alpha r_{\text {max }}$ is considered to be 1 , the runoff can be described without adding a new parameter to the model.

\subsection{Objective function for model optimization}

From the RR and ETO measurements and applying the following conceptual model, a model of peat water storage change was constructed. Four parameters, Kc, $\alpha$, Imax and Semax needed to be estimated in order to model the daily water storage changes. The parameters were estimated by comparing the observed stored water change Se (equation 1) and the calculated storage changes in the effective porosity $(\mathrm{Sm}+\mathrm{Se})$. The parameters were optimized by using a nonlinear excel solver ${ }^{\circledast}$ with a convergence of about 0.0001 and an accuracy of about $5 \%$.

The objective function selected to calibrate the models is of the least-squares type. It is based on the formulation proposed by Nash and Sutcliffe (1970) and given by:

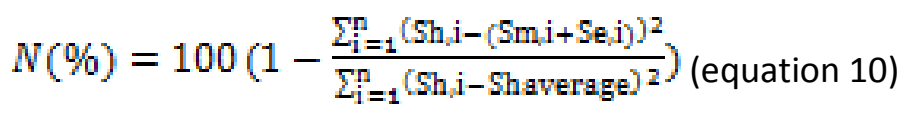

These measures vary between $-\infty$ and $100 \%$ for perfect agreement and are easy to interpret. They quantify the ability of the model to explain WT variance, i.e. the improvement achieved by any model in simulating WT compared to a basic reference model simulating a constant WT equal to the mean observed one.

Klemes (1986) proposed a hierarchical assessment methodology to test model performances in calibration simulation mode (split sample test). This scheme places great importance on model verification by assessing the transposability of models in time or under changing environmental conditions. For each site, the models were successively calibrated on a sub-period (2009-2010 dataset) and then tested in verification mode on all the remaining periods (see the calibrated and verified Nash values in Table 3). The sensitivity of parameters was defined as the value that needs to 
be added to or subtracted from the best fit results to decrease the Nash criteria by about $5 \%$ (Table 3).

\section{Field results}

\subsection{Catchment and discharge}

The drainage network inferred from WT measurements conducted in March 2009 evidenced that the Peatland is divided into two watersheds, outflowing into the La Guette river close to the discharge points Q0 and Q1 (Fig.1). The watershed area is respectively $2.610^{5} \mathrm{~m}^{2}$ and $4.10^{4} \mathrm{~m}^{2}$ for the western and the eastern areas. Q0 percolation for the days without runoff ranged from 0.3 to $0.8 \mathrm{l} / \mathrm{s}$ (Fig.3). The specific yield was estimated to be about $60 \mathrm{~mm} / \mathrm{year}$.

\subsection{WT fluctuations}

WT fluctuations were monitored during 3 hydrological cycles. Table 1 presents the annual averages, the minimum and the maximum of the WT depth, the precipitation (PP) and the evapotranspiration (ETO). The average values of the WT changed with the 3 hydrological cycles. In the DO well, for example, the average WT depth varied from 83 to $163 \mathrm{~mm}$. In all the observation wells a WT decrease of $80 \mathrm{~mm}$ in 2009 was observed. The dynamics of the WT changed with time. Figure $3 \mathrm{~A}$ shows an example of the effective rainfall and stored water time evolution observed in the WO observation wells, with a low variability before June 2009, when a strong decrease occurred. After June 2009 , greater variability is observed.

The maximum value of the WT depth (which delineates the acrotelm and the catotelm, Ingram, 1983), decreased by about $140-240 \mathrm{~mm}$ below the surface between the hydrological cycle 20082009 and $2009-2010$ (Table 1). The highest value $(424 \mathrm{~mm})$ was recorded in an area invaded by vascular plants. In summer the deepest values of WT appear to be correlated with annual evapotranspiration. The 2009-2011 hydrological cycles show that the ETO are higher than the 30 years' average. 
The minimum values of the WT depth were recorded in winter and changed over the years. In the WO wells, minimum values were 56, 101 and $74 \mathrm{~mm}$ depth for years receiving 767, 700 and $744 \mathrm{~mm}$ of precipitation respectively (Table1). In winter WT depth appears to be negatively correlated with the annual precipitation ( $R=-0.896$ and $R=-0.998, n=3$, for DO and WO respectively).

\subsection{Daily change of water storage $(\Delta S p)$}

The effective porosity varied between 3 to $70 \%$ decreasing with the depth, and the retention porosity was 20 to $84 \%$. The specific storage (Ss) ranged from 0 to $1810^{-4} \mathrm{~cm}^{-1}$. This value means that water release by peat compressibility was on the same order of magnitude as water release through effective porosity. From these measurements, water storage in the peat column was computed with equation 1 . The drainage table (Table 2) shows the amount of water stored in the peat for a given WT in effective and retention porosity. The maximum storage capacity in effective peat porosity (Semax) in the four observation wells was found to be $66-107 \mathrm{~mm}$ (Table 2). The maximum amount of water located in the retention porosity ranged from 300 to $612 \mathrm{~mm}$.

\section{Model of WT fluctuations.}

For each observation well, the optimization of the four parameters (Kc, $\alpha p, I$ and Semax) with equation 10 gives the optimized parameters presented in Table 3 . The objective function shows values up to $80 \%$ for the calibration stage and up to $70 \%$ for the validation stage. The proposed model can be considered as consistent with WT measurements. Figure $3 \mathrm{~b}$ shows that the model calibrated with the 2009-2010 WT dataset reproduces the WO WT throughout the period of observation. The same model estimates the daily runoff in accordance with observed runoff (Figure 4). This suggests that the WT dependent runoff coefficient model is efficient and takes into account part of the possible feedback between WT and runoff.

\subsection{Impact of vascular plants on the WT $(\mathrm{Kc})$}


The crop coefficient was found to be 0.20 in the open areas versus 0.29 in closed ones. These results are in agreement with Campbell and Williamson (1997) who found a value of 0.22 in an open peatbog, and with theory (Spieksma et al. 1997) which suggests that vascular plants increase evapotranspiration. Vascular plants increase the ET of the peatland, and increase the water deficit calculated for these 3 years. Vascular plants increase the summer drought effect on the WT, and thus increase the thickness of the acrotelm layer, exposing previously catotelm peat to aerobic conditions.

From this model, an average water balance of the peatland can be estimated for open and closed areas (Table 4). Over the 3 years studied, the water storage in peat decreased, showing that the inter-annual variability of precipitation and evapotranspiration influenced the peat water balance and the WT. The water storage decrease was $20 \mathrm{~mm} /$ year higher in closed areas, showing that vascular plants contributed to the drying of the peatland.

For the period 2008-2011, the model describes the observed WT fluctuations with a crop coefficient (Kc) that is time-independent. This means that the invasion of the site by vascular plants is not directly the cause of the observed WT change between 2008 and 2011.

\subsection{Impact of vascular plants on the water flows ( $\alpha p$ and $\alpha r$ )}

The percolation coefficients were always less than $310^{-3} 1 / \mathrm{s}$. Thus the averaged percolation rate was about $<60 \mathrm{~mm} /$ year and be considered negligible for the observation wells located in the closed areas with vascular plants. This is close to Van Seters and Price (2001), who omitted percolation in their water balance of Quebec peatlands. The runoff coefficient changes with the WT depth (equation 9). The yearly average value was close to 1 and it fell to 0.8 during the dry summer period, in accordance with the usual values in wetland (Fetter, 1994).

Percolation in peat is slow compared to runoff. The comparison between the four modeled WT shows that an increase in the water consumption of the vascular plants decreased the percolation velocities into the peat (Table 3). These mechanisms act to enable the water supply of the plants in dried peat. Thus, in the areas with vascular plants, without subsurface flows, the proposed model can be reduced to a 3-parameter model including runoff and storage reservoirs. 


\subsection{Saturation state of the peat (Semax)}

Table 3 shows that in La Guette peatland the calculated maximum storage (Semax) was $81-138 \mathrm{~mm}$, which is consistent with the maximum storage capacity observed in effective porosity (Table 2).

Therefore the water stored in the retention porosity (Sr) does not directly influence the WT fluctuations in the effective porosity (Se). However, the water from retention and unsaturated zones may be used by evapotranspiration. In a Sphagnum peatland (Fuhrengawa Mire), estimates of water balance showed that an almost identical amount of water lost to evapotranspiration was re-supplied from deeper layers to the surface (Yazaki et al., 2006). Schlotzhauer and Price (1999) showed that the volumetric water content of unsaturated zones has a linear relationship with WT depth. Flows occur in the unsaturated and in the retention zones, but they are directly $(<1$ day) offset by the percolation reservoir. Thus this model cannot address the question of water mixing between effective and retention reservoirs.

\subsection{Equilibrium positions of the WT in winter (Imax)}

The peat appeared to be rarely fully saturated (Se < Semax in Fig.3) and the WT depth in winter changed over the years (Fig.3). The calculated Imax values (0.2 to $2.4 \mathrm{~mm} /$ day) were on the same order as the usual hydraulic conductivity of peat (Fetter, 1994), suggesting that infiltration is the limiting factor controlling the maximum WT observed during winter. Due to the low infiltration rate, saturation of the peat (Semax, $128 \mathrm{~mm}$ for the WO in Figure 3) is rarely reached in this peatland, even in winter. The runoff reservoir $(\mathrm{Sm})$ can contain water, even if the percolation reservoir (Se) is not saturated. The model suggests that the observed WT variability in winter is controlled by input / output of water in the Se reservoir. In winter, when flows in the runoff reservoir are observed, the peat is recharged by infiltration (Table 4). The WT is in equilibrium with respect to the Se reservoir input $(\operatorname{Imax})$ and output $(\mathrm{ETp}+\mathrm{P})$. Related to these two terms, the WT in winter will stabilize at a given depth. In this disturbed peatland, the maximum storage capacity and overland flows are not the dominant parameters to explain the amount of stored water in the peat. 
Similarly, when the peat is submitted to a strong WT decrease (here a strong drought in summer 2009), the calculation suggests that the peat will need more than one year to reach a saturated state again due to the low rate of infiltration. If another drought occurs in the following years, the peat may accumulate the effects of the two droughts and the WT will strongly decrease. In this disturbed peatland, the air entrapment between runoff and the effective reservoirs (Semax-Se) caused by the 2009 summer drought was around $30 \mathrm{l} / \mathrm{m}^{2}$ or $30 \%$ of the water storage capacity. This air entrapment is observed even in the winter following the drought and several hydrological cycles are required before it disappears, showing that a drought may have a long-term effect on peat hydrology. The presence of $30 \%$ of air blocked in the peat for several years can be useful to understand the biogeochemical process controlling the $\mathrm{C}$ cycle in disturbed peatland.

\section{Conclusion}

This paper has investigated the water table dynamics in a peatland showing a wide range of water table fluctuations. A reservoir model of water table fluctuations in a multi-porosity peat is proposed from a literature review, by calculating the stored water in effective porosity of the peat from precipitation and evapotranspiration datasets. Calculations include vascular plant consumption through a crop coefficient, using a maximum infiltration rate and storage capacity, runoff and percolation coefficients. The runoff coefficient is considered to be water table dependent. This model has been tested on a peatland that has experienced strong water table fluctuations caused by summer drought and/or by vascular plant invasion. A water table dependent runoff model is able to to describe the WT fluctuations in a peatland. With this model, vascular plants are found to increase evapotranspiration and to limit percolation. The maximum water tables in winter are found to change over the years and are related to an equilibrium between infiltration versus percolation plus evapotranspiration.

In this disturbed peatland, even if overland flows occur after a drought, the re-saturation of effective porosity is slow, with about $30 \%$ of air trapped in the peat porosity. The effects of drought on peat 
saturation are observed on more than one hydrological cycle. This can significantly affect the biogeochemical processes controlling the $\mathrm{C}$ cycle in peatland.

\section{Acknowledgements}

The authors would like to thank all the persons involved in the field work: Axel Aurouet, Emilie Rivoire, Aurore Aubineau and Alice Canelle. S. Gogo's salary was financed by the CG 45, the Spatioflux program and the VOLTAIRE Labex. The peatland is part of the site network certified by the National Institute of Sciences of the Universe (INSU) as Observation Service of Peatlands. 


\section{References:}

Binet S., Mudry J., Bertrand C., Guglielmi Y., Cova R. (2006). Estimation of quantitative descriptors of northeastern Mediterranean karst behavior: multiparametric study and local validation of the SiouBlanc massif (Toulon, France). Hydrogeology Journal (14) 1107-1121

Binet S., Guglielmi Y., Bertrand C., Mudry J. (2007). Unstable rock slope hydrogeology: insights from the large-scale study of western Argentera-Mercantour hillslopes (South-East France). Bulletin de la Société Géologique de France (178) 159-168

Campbell D.I. and Williamson J.L. (1997). Evaporation from a raised peat bog. Journal of Hydrology (193) $142-160$

Carlesso R., Spohr R.B., Eltz F.L.F., Flores C.H. (2011). Runoff estimation in southern Brazil based on Smith's modified model and the Curve Number method. Agricultural Water Management (98) 10201026

Charlier J.-B., Bertrand C., Binet S., Mudry J., Bouillier N. (2010). Use of continuous measurements of dissolved organic matter fluorescence in groundwater to characterize fast infiltration through an unstable fractured hillslope (Valabres rockfall, French Alps). Hydrogeology journal (18) 1963-1969

Charmoille A., Binet S., Bertrand C., Guglielmi Y., Mudry J. (2009). Hydraulic interactions between fractures and bedding planes in a carbonate aquifer studied by means of experimentally induced water-table fluctuations (Coaraze experimental site, southeastern France). Hydrogeology journal (17) $1607-1616$

Chaubey I. and Ward G. M. (2006). Hydrologic Budget Analysis of a Small Natural Wetland in Southeast USA. Journal of Environmental Informatics 8(1) 10-21

Daniels S.M., Agnew C.T. , Allott T.E.H., Evans M.G. (2008). Water table variability and runoff generation in an eroded peatland, South Pennines, UK. Journal of Hydrology (361) 214-226 
Fetter CW. (1994) Applied hydrogeology. 3rd ed. Prentice-Hall: Englewood Cliffs, NJ, 691.

Fiorillo F. (2011). Tank-reservoir drainage as a simulation of the recession limb of karst spring hydrographs. Hydrogeology journal (19) 1009-1019

Gogo S., Guimbaud C., Laggoun-Defarge F., Catoire V. Robert C. (2011a). In situ quantification of $\mathrm{CH}_{4}$ bubbling events from a peat soil using a new infrared laser spectrometer. Journal of soils and sediments (11) 545-551

Gogo S., Laggoun-Defarge F. Delarue F., Lottier N. (2011b). Invasion of a Sphagnum-peatland by Betula spp and Molinia caerulea impacts organic matter biochemistry. Implications for carbon and nutrient cycling. Biogeochemistry (106) 53-69

Gorham E. (1991) Northern peatland: role in the carbon cycle and probable responce to climate warning. Ecological application (2), 182-195

Gruber S. and Peckham S. (2009). Land-surface parameters and objects in hydrology. In Geomorphometry: Concepts, Software, Applications. Eds. T. Hengl and H.I. Reuter, Elsevier. 171-185 Holden J. and BurtT.P. (2003). Hydrological studies on blanket peat: the significance of the acrotelmcatotelm model. Journal of Ecology (91) 86-102

Holden J., Kirkby M.J. , Stuart M.J., Lane N., Milledge D.G. Brookes C.J., Holden V., McDonald A.T. (2008). Overland flow velocity and roughness properties in peatlands Water Resources Research (44) W06415

Ingram H.A.P. (1983). Hydrology. Ecosystems of the World 4A, Mires: swamp, bog, fen and moor (ed. A.J.P. Gore), 67-158. Elsevier, Oxford.

Kennedy G.W. and Price J.S. (2005). A conceptual model of volume-change controls on the hydrology of cutover peats. Journal of Hydrology (302) 13-27 
Klemes, V. (1986). Operational testing of hydrological simulation models. Hydrological Sciences Journal (31), 13-24.

Lashof D.A., De Angelo B., Saleska S.R. Harte J. ( 1997). Terrestrial ecosystem feedback to global climate change. Ann. Rev. Energy. Env.(22) 75-118

Limpens J., Berendse F., Blodau C., Canadell J. G., Freeman C., Holden J., Roulet N., Rydin H., Schaepman-Strub G. (2008).Peatlands and the carbon cycle: from local processes to global implications ? a synthesis Biogeosciences Discussions (5) 1379-1419

Maillet E. (1905) Essais d'Hydraulique souterraine et fluviale [Underground and river hydrology]. Hermann, Paris, $218 \mathrm{pp}$

Morris P.J., Waddington J.M., Benscoter B.W., Turetsky M.R. (2011). Conceptual frameworks in peatland ecohydrology: looking beyond the two-layered (acrotelm-catotelm) model. Ecohydrology (4) $1-11$

Moore T.R. and Knowles R. (1989). The influence of water table levels on methane and carbon dioxide emissions from peatland soil. Canadian journal of soil sciences (69) 33-38

Nash, J.E., Sutcliffe, J.V. (1970). River flow forecasting through conceptual models. Part I: a discussion of principles. Journal of Hydrology (27) 282-290

Ours D.P., Siegel D.I., Glaser P.H. (1996). Chemical dilatation and the dual porosity of humified bog peat. Journal of hydrology (196) 348-360

Perrin C., Michel C., Andreassian V. (2001). Does a large number of parameters enhance model performance? Comparative assessment of common catchment model structures on 429 catchments. Journal of Hydrology $242275-301$

Quinton W. L. and Marsh P. (1999). A Conceptual Framework for Runoff Generation in a Permafrost Environment. Hydrological Processes (13) 2563-2581 
Restrepo J.I., Montoya A.M., Obeysekera J (1998). A Wetland Simulation Module for the MODFLOW Ground Water Model. Ground Water (36) 764-770

Rosenberry D.0., Winter T.C. (1997). Dynamics of water-table fluctuations in an upland between two prairie-pothole wetlands in North Dakota. Journal of Hydrology (191) 266-289

Sarkkola S., Koivusalo H., Laurén A., Kortelainen P., Mattsson T., Palviainen M., Piirainen S., Starr M., Finér L. (2009). Trends in hydrometeorological conditions and stream water organic carbon in boreal forested catchments. Science of the Total Environment (408) 92-101.

Schlotzhauer S.M. and Price J.S. (1999) Soil water flow dynamics in cutover peat field. Water resources research (35) 3675-3683

Spieksma J.F.M., Moors E.J., Dolman A.J., Schouwenaars J.M. (1997) Modelling evaporation from a drained and rewetted peatland. Journal of Hydrology (199) 252-271

Tetzlaff D., Soulsby C., Waldron S., Malcolm I. A., Bacon P.J., Dunn S.M., Lilly A. and Youngson A.F. (2007). Conceptualization of runoff processes using a geographical information system and tracers in a nested mesoscale catchment. Hydrological Processes (21) 1289-1307

Van Seters T.E. and Price J.S. (2001). The impact of peat harvesting and natural regeneration on the water balance of an abandoned cutover bog, Quebec. Hydrological Processes (15) 233-248

Violette A., Goddéris Y., Maréchal J.-C., Riotte J., Oliva P. , Kumar M.S.M., Sekhar M., J.-J. Braun (2010). Modelling the chemical weathering fuxes at the watershed scale in the Tropics (Mule Hole, South India): Relative contribution of the smectite/kaolinite assemblage versus primary minerals. Chemical Geology (277) 42-60

Yazaki T., Urano S., Yabe K. (2006). Water balance and water movement in unsaturated zones of Sphagnum hummocks in Fuhrengawa Mire, Hokkaido, Japan. Journal of Hydrology (319) 312-327 
Weiss R., Shurpali N.J., Sallantaus T., Laiho R., Laine J., Alm J. (2006). Simulation of water table level and peat temperatures in boreal peatlands. Ecological Modelling (192) 441-456.

Wanga J., Sammis T.W., Andales A.A., Simmons L.J. , Gutschick V.P. , Miller D.R. (2007). Crop coefficients of open-canopy pecan orchards. Agricultural Water Management (88) 253- 262

Worrall F., Armstrong A. , Holden J. (2007). Short-term impact of peat drain-blocking on water colour, dissolved organic carbon concentration, and water table depth. Journal of Hydrology (337) 315-325 
FIGURES:

Fig.1: Map of the la Guette peatland: location of the peatland (blue), of the piezometers (WO, DO, WC and DC); accumulation flux of water calculated from the piezometric map (blue lines), watersheds (dashed lines) and discharge areas (Q0 and Q1). Elevation in meter above sea level.

Fig.2: Conceptual model of water balance in a peatland: (1) Recharge; (2) evapotranspiration: 2a in the runoff reservoir, $2 \mathrm{~b}$ in the percolation reservoir; (3) Infiltration; (4) percolation; (5) Runoff; Sm: runoff reservoir = dashed area; Se: percolation reservoir; Semax: maximum storage capacity of the Se reservoir; w: width of the channel at the water table surface

Table 1: Annual average, minimum and maximum water table depth, in millimeters for the 4 observation wells compared to the precipitation (RR) and evapotranspiration (ETO) in mm.

Table 2: Drainage Table (in millimeters), measured

Fig.3: Water storage fluctuations (in liter $/ \mathrm{m}^{2}$ ) through time in the WO well. (a) Effective rainfall ( $\mathrm{mm} /$ day); (b) comparison between observed (Sp) and calculated $(\mathrm{Sm}+\mathrm{Se})$ stored water. The dashed line represents the Smax.

Fig.4: Discharge in autumn 2010. (a) Effective rainfall; (b) comparison between observed discharge (Q0) and discharge $(R+P)$ calculated from a model calibrated with WT measurements. 
Table 3: Parameter estimations and sensitivity of the model for open / closed observation wells.

Table 4: Water balance of the La Guette peatland for open and closed observation wells. 


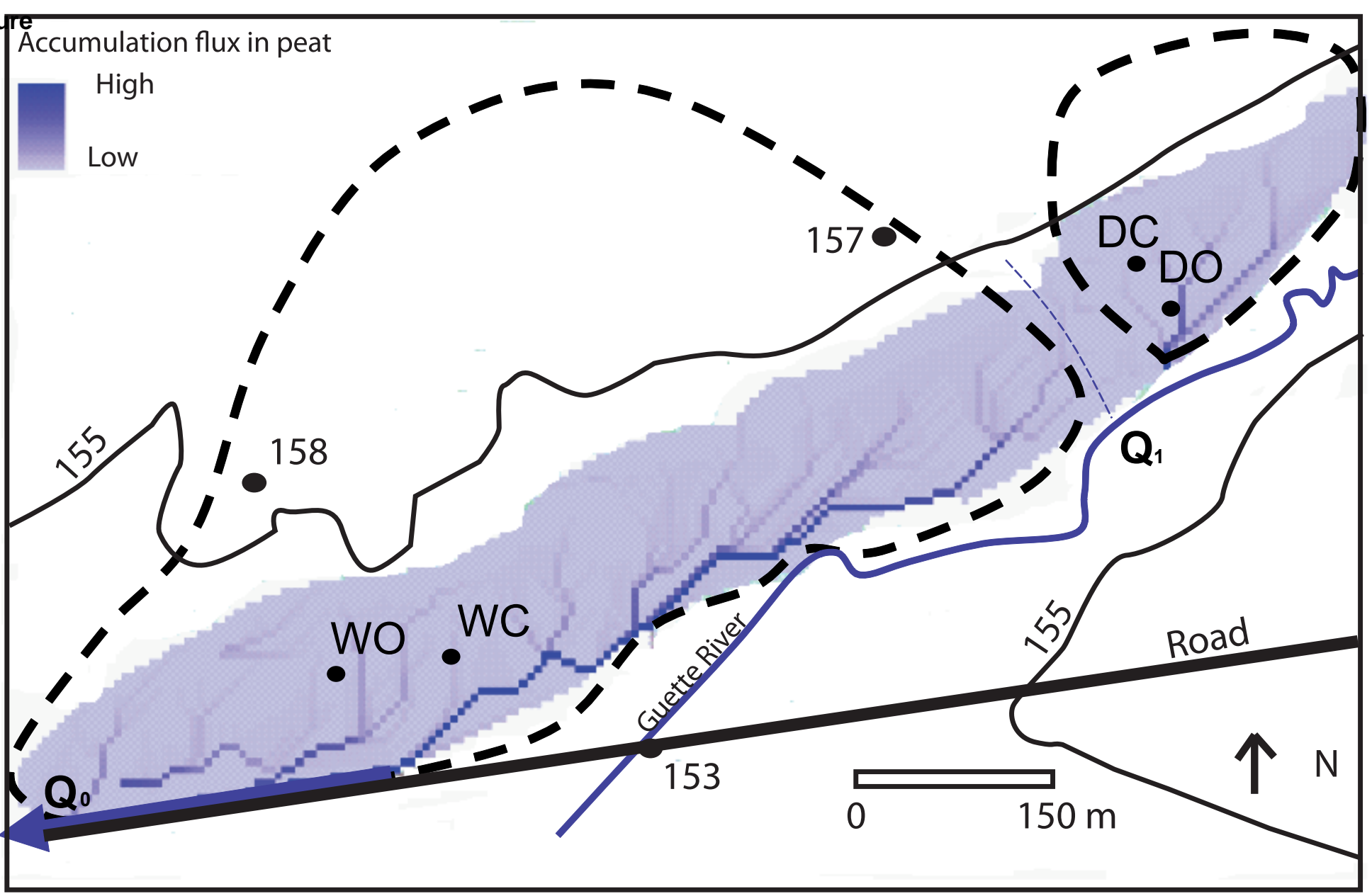


Figure

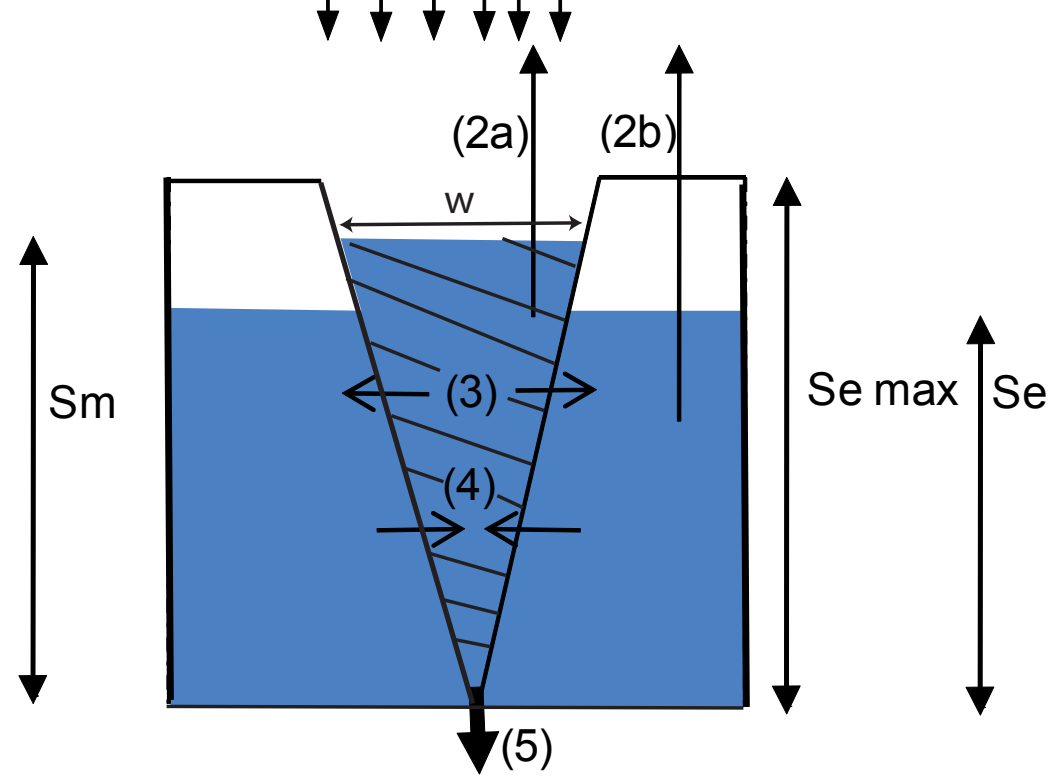


Figure
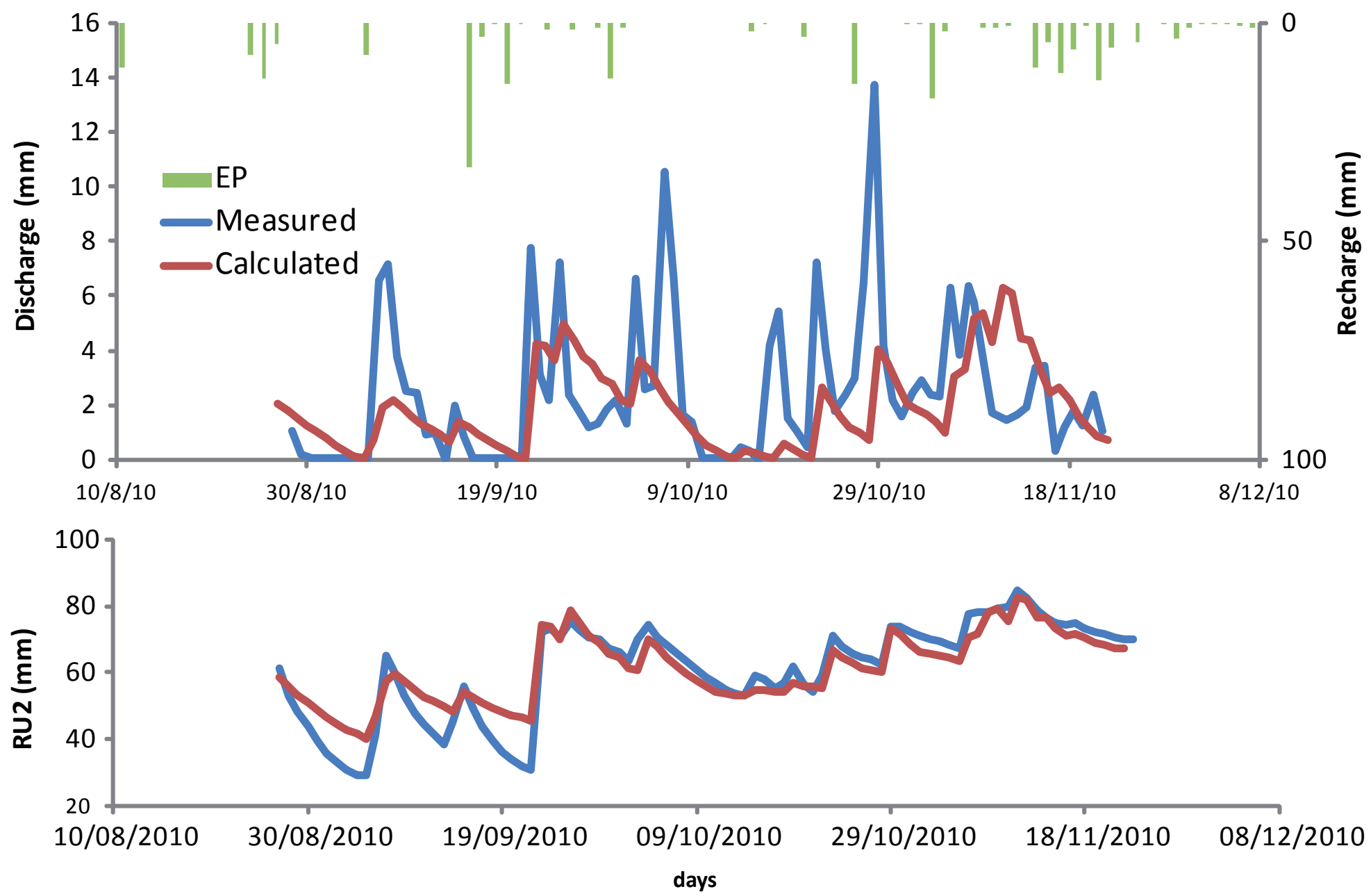


\begin{tabular}{lcccccc} 
& \multicolumn{3}{c}{ W. Open } & \multicolumn{3}{c}{ W. Closed } \\
& Aver. & Min. & Max & Aver. & Min. & Max \\
\hline $08-09$ & 90 & 127 & 56 & 77 & 136 & 49 \\
$09-10$ & 171 & 267 & 101 & 149 & 271 & 77 \\
$10-11$ & 180 & 329 & 74 & $/$ & $/$ & $/$
\end{tabular}




\begin{tabular}{ccccccc} 
& \multicolumn{2}{c}{ W. Open } & \multicolumn{2}{c}{ D. Open } & \multicolumn{2}{c}{ W. Closed } \\
Depth $(\mathbf{m m})$ & Se & Sr & Se & Sr & Se & Sr \\
\hline 0 & 128 & 408 & 132 & 449 & 90 & 305 \\
25 & 111 & 401 & 116 & 440 & 73 & 298 \\
75 & 91 & 373 & 96 & 412 & 53 & 270 \\
125 & 83 & 335 & 87 & 374 & 45 & 232 \\
175 & 77 & 294 & 82 & 334 & 39 & 192 \\
225 & 71 & 255 & 78 & 294 & 33 & 152 \\
275 & 68 & 215 & 74 & 254 & 30 & 112 \\
325 & 62 & 177 & 68 & 215 & 24 & 74 \\
375 & 47 & 145 & 59 & 179 & 9 & 42 \\
425 & 40 & 105 & 53 & 144 & 2 & 3 \\
475 & 19 & 79 & 38 & 119 & 0 & 0 \\
max. & 0 & 0 & 0 & 0 & &
\end{tabular}


Crop coef.,

$\mathrm{Kc}(/)$

$0.21 \pm 0.02$

0.20

0.27

$\pm 0.02$

Semax, $(\mathrm{mm})$

$138 \pm 5$

113

$\pm 0.007$

$81 \pm 3$

Infiltration, I

( $\mathrm{mm} / \mathrm{d}$ )

$0.25 \pm 0.03$

$0.22 \pm 0.012$

$0.24 \pm 0.05$

Percolation

coef $\alpha,(1 / d)$

3.E-03 \pm 0.0002

7.E-07 \pm 0.0002

$<0.0003$

Calibrated

Nash (\%)

82

81

80

Verified Nash

(\%)

76

77

72 
Water balance for 2009 - 2011 period in $\mathrm{mm} /$ Years

Wet Open

Dry Open

Wet Closed

Actual evapotranspiration (ET)

Actual evapotranspiration in peat (ETp)

198

183

$64 \quad 67$

183

Runoff (R)

587

615

63

Infiltration (I)

77

52

623

Percolation (P)

32

0

63

storage change $(\Delta S p)$

$-48$

$-30$

0

$-38$ 